\title{
Cubosome nanoparticles potentiate immune properties of immunostimulants
}

\author{
This article was published in the following Dove Press journal: \\ International Journal of Nanomedicine \\ 29 July 2016 \\ Number of times this article has been viewed
}

\author{
Zhenguang Liu \\ Li Luo \\ Sisi Zheng \\ Yale Niu \\ Ruonan Bo \\ Yee Huang \\ Jie Xing \\ Zhihua Li \\ Deyun Wang \\ Institute of Traditional Chinese \\ Veterinary Medicine, College of \\ Veterinary Medicine, Nanjing \\ Agricultural University, Nanjing, \\ People's Republic of China
}

Correspondence: Deyun Wang Institute of Traditional Chinese Veterinary Medicine, College of Veterinary Medicine, Nanjing Agricultural University, I Weigang Road, Nanjing 210095, People's Republic of China

Tel +862584395203

Fax +862584398669

Email dywang@njau.edu.cn

\begin{abstract}
Cubosomes have been explored as drug and antigen carriers in the past few years. A few reports have described that cubosomes can enhance the ability of immunostimulants to generate strong immune responses. Polysaccharide (PS), an immunostimulant, has been reported to be a promising adjuvant for vaccines. Herein, we incorporated PS into cubosomes to generate PS-cubosome (Cub-PS) nanoparticles, and Cub-PS was characterized by small-angle X-ray scattering scattering and cryo-field emission scanning electron microscopy. The immunological activity of Cub-PS was compared with that of $\mathrm{Cub}$ and PS. The results demonstrated that Cub-PS elicited more potent immune responses than Cub or PS alone. The enhanced immune responses might be attributed to the promotion of antigen transport into draining lymph nodes and efficient dendritic cell activation and memory T-helper cell differentiation in draining lymph nodes. Overall, these findings indicate that cubosomes have the potential to enhance the ability of immunostimulants to generate an immune response.
\end{abstract}

Keywords: cubosomes, polysaccharides, cryo-FESEM, lymph nodes, dendritic cells, memory T-helper cells

\section{Introduction}

Subunits of recombinant proteins and killed viruses are largely used as vaccine candidates, as they are less toxic than live pathogens. Although these compounds offer advantages, they are often poorly immunogenic. An ideal vaccine should induce strong cellular and humoral responses. Thus, it is necessary to develop vaccine adjuvants to enhance vaccine immune responses. ${ }^{1}$ The term adjuvant refers to additives or vaccine carriers that improve and stimulate the adaptive immune response or innate immune system. One promising strategy is the coadministration of the antigen vaccines with active immunostimulants to increase the immune response. ${ }^{2,3}$ In addition, lipid-based particulate systems that are currently under investigation and show promise as potential carriers for antigen vaccines and immunostimulants include liposomes and related structures. A majority of studies investigating the adjuvant response to lipid-based particles have focused on lamellar phase materials such as unilamellar/multilamellar vesicles, liposomes, or poly(lactic-co-glycolic acid) (popularly known as PLGA).,5

Cubosomes based on the cubic phase of monoolein or phytantriol have received intense attention for their ability to act as carriers for delivery of bioactive materials, ${ }^{6-9}$ and in targeted detection. ${ }^{10}$ Cubosomes have a special nanostructure, being composed of a lipid bilayer and two water channels, which can offer high encapsulation of a drug or its active components due to their high surface area. ${ }^{11}$ A recent study indicated the adjuvant property of cubosomes encapsulating ovalbumin and showed that they were more efficient at generating antigen-specific cellular responses when compared 
to alum. ${ }^{11}$ However, there is not much research indicating whether cubosomes could enhance the ability of immunostimulants to generate strong immune responses.

Polysaccharides (PSs) extracted from Ganoderma lucidum were shown to activate the host immune system, leading to the production of various $\mathrm{T}$-helper $1\left(\mathrm{~T}_{\mathrm{h}} 1\right)$-biased cytokines, ${ }^{12}$ which indicates the potential of immunostimulants. However, the PSs also have some disadvantages, such as having a nonfocused action scope, being dependent on large doses, and having a brief biological half-life, which may limit future applications. In our laboratory, we have confirmed that PS liposomes can generate stronger humoral responses compared to PSs alone. ${ }^{13}$ Furthermore, we were able to prepare PSs containing nanoparticles and achieve low levels of detectable antibody and innate immune responses with inactivated porcine circovirus type 2 (PCV-II) viruses.

Consistent with recent observation, ${ }^{14,15}$ delivery of antigen and immunostimulants in separate nanoparticles induced a stronger immune response than delivery of both in the same nanoparticle. In this study, we incorporated PS into cubosomes to generate cubosome-PS (Cub-PS) nanoparticles. The Cub-PS nanoparticle was characterized by small-angle X-ray scattering scattering (SAXS) and cryo-field emission scanning electron microscopy (Cryo-FESEM). The in vitro cell toxicity of Cub-PS was evaluated in peritoneal macrophages. Finally, the immunogenicity was evaluated in mice by measuring the immune responses induced by subcutaneous coadministration of inactivated PCV-II viruses as "nanoantigen" and Cub-PS, compared to administration of Cub or PS formulation alone. The enhanced immune responses elicited by Cub-PS might be attributed to promotion of antigens transporting into draining lymph nodes and efficient dendritic cell (DC) activation and memory T-helper cell differentiation in draining lymph nodes.

\section{Materials and methods Materials}

Phytantriol (Phy, 98.0\%) was purchased from TCI (Tokyo, Japan). Pluronic F127 was purchased from Sigma-Aldrich Co (St Louis, MO, USA). The purified Ganoderma lucidum PSs GLP ( $\geq 98 \%$ purity) were obtained from CiYuan Biotechnology Co, Ltd, Shanxi, People's Republic of China. Propylene glycol was purchased from Yuwang Industrial Co, Ltd (Shandong, People's Republic of China). 3-(4,5-Dimethylthiazol-2-yl)-2,5diphenyltetrazolium bromide (MTT) was purchased from Amresco LLC (Solon, OH, USA). RPMI 1640 was purchased from Thermo Fisher Scientific (Waltham, MA, USA). Inactivated PCV-II viruses were a gift from the National Research Center of Veterinary Biologicals Engineering and Technology. ISA 206 was purchased from Seppic Inc. (Paris, France).

\section{Preparation of cubosomes}

Briefly, $100 \mathrm{mg}$ of phytantriol and $75 \mathrm{mg}$ of propylene glycol were dissolved in $2 \mathrm{~mL}$ ethanol at $25^{\circ} \mathrm{C}$. Then, the ethanol solution was added, dropwise, to $20 \mathrm{~mL}$ of a solution of Pluronic F127 (0.5 mg/mL) under continuous vortexing. The mixtures were vortex mixed and then evaporated using a rotary evaporator for 30 minutes. After removing the ethanol completely, the dispersant was homogenized by ultrasonication (MisonixXL2000, Misonix Incorporated, Nanjing, People's Republic of China) in pulse mode (5-second pulses interrupted by 5 -second breaks) at $70 \%$ of maximum power for 10 minutes. For the PS-loading dispersion, $10 \mathrm{mg}$ of PS was added into the solution of Pluronic F127 dispersant, and the preparation was done in the same way. Cub-PS-antigen (Ag), Cub-Ag, and PS-Ag were prepared by mixing the Cub-PS, PS, and Cub solutions with PCV-II solution and vortexing for 5 minutes.

\section{Encapsulation efficiency of PS}

One milliliter of the Cub-PS dispersions was centrifuged for 30 minutes at $12,000 \mathrm{rpm}$ to separate the entrapped PS from the unentrapped moieties. Exactly $0.5 \mathrm{~mL}$ of the supernatant was diluted with $0.5 \mathrm{~mL}$ Triton X-100 (Shanghai Yuanye Biotechnology Co, Ltd, Shanghai, People's Republic of China) to lyse any lipid fragments and was analyzed using the vitriol-phenol method; the PS content was referred to as the content of free PS. In addition, $0.5 \mathrm{~mL}$ of the Cub-PS dispersions added in the centrifuge tube was mixed with $0.5 \mathrm{~mL}$ of Triton X-100. Subsequently, the solution was used to assay the content of PS using the vitriol-phenol method, ${ }^{15}$ and this solution was termed the amount of PS in $0.5 \mathrm{~mL}$ of Cub-PS dispersions. The formula for Cub-PS encapsulation efficiency (EE) is expressed as follows:

$$
\mathrm{EE} \%=\left(1-Q_{\mathrm{f}} / Q_{\mathrm{t}}\right) \times 100 \%
$$

where $Q_{\mathrm{f}}$ is the amount of free PS and $Q_{\mathrm{t}}$ is the amount of total PSs in $0.5 \mathrm{~mL}$ of Cub-PS dispersions.

\section{Size and surface charge}

Size and zeta $(\zeta)$ potential of the cubosomes were determined using a Zetasizer Nano ZS (Malvern Instruments, Malvern, UK). Particle size and the polydispersity index (PDI) were measured using a high-performance dynamic light scattering (DLS) device with Malvern Zetasizer Nano ZS at a fixed angle of $90^{\circ}$. The cubosome dispersions were sonicated for 30 seconds and then diluted with distilled water $(0.2 \mathrm{~mL} \rightarrow$ $1.0 \mathrm{~mL}$ ). The zeta potential was measured using the zeta potential analyzer attachment at $25^{\circ} \mathrm{C}$. 


\section{SAXS studies}

SAXS measurement was performed on a Bruker NanoSTAR SAXS. The instrument source was a copper rotating anode (0.3 mm filament) operating at $45 \mathrm{kV}$ and $110 \mathrm{~mA}$, fitted with a cross-coupled Göbel mirror, resulting in a $\mathrm{Cu} \mathrm{K} \alpha$ radiation wavelength of $1.54 \AA$. The Cub-PS samples were equilibrated at $25^{\circ} \mathrm{C}$ for 30 minutes before the collection of a scattering pattern for 30 minutes.

\section{Cryo-FESEM studies}

Cubosomes were placed in brass rivets and plunge-frozen in liquid propane. The cubosomes were transferred into the cryochamber (K1250X, Quorum Technologies, Ashford, UK) of the microscope (S-4800; Hitachi, Tokyo, Japan), which was held at a temperature of $-140^{\circ} \mathrm{C}$. The samples were then sublimed at $-90^{\circ} \mathrm{C}$ and then coated with platinum. The cubosomes were viewed once at $-140^{\circ} \mathrm{C}$, at an accelerating voltage of $3 \mathrm{kV}$ and a working distance of $6 \mathrm{~mm}$.

\section{Cell viability tests}

Cell cytotoxicity tests were conducted using peritoneal macrophages. Peritoneal macrophages were collected and purified as described earlier. ${ }^{16}$ The macrophages were plated into a 96-well plate at a density of $5 \times 10^{5}$ cells per well and cultured at $37^{\circ} \mathrm{C}$ in a humidified atmosphere $\left(5 \% \mathrm{CO}_{2}\right.$ and $95 \%$ air $)$. $\mathrm{PS}, \mathrm{Cub}$, and Cub-PS were introduced into the macrophages, and the cells were cultured for 24 hours. The cells cultured in blank medium were taken as the control. After 24-hour incubation, cell viability was evaluated using the MTT method.

\section{Effect on cluster of differentiation (CD)4- to-CD8 ratio}

Lymphocytes were harvested from the mice spleens and seeded into 24 -well plates at $1 \times 10^{6}$ cells per well before incubation with PS, Cub, and Cub-PS for 48 hours. The cells were then stained with antibodies, including anti-CD3e-phycoerythrincyanine5 (anti-CD3e-PE-Cy5), anti-CD8-PE, and anti-CD4fluorescein isothiocyanate (FITC) antibodies (all from BD Biosciences, San Jose, CA, USA). The cells were analyzed using fluorescence-activated cell sorting analysis.

\section{Immunization}

Female BALB/c mice were housed in an animal research laboratory under standard conditions in top-filtered cages. All the animals were fed a regular diet and given acidified water without antibiotics. All the animals remained in good health for the duration of the study. During the evaluation, 60 female BALB/c mice (6-8 weeks old, 18-22 g) were divided into five groups $(n=12)$. The mice were immunized by subcutaneous injection twice at 1-week intervals. Two groups were treated with ISA 206 (water-in oil-water emulsions [W/O/W], positive control groups) containing inactivated PCV-II viruses and phosphate-buffered saline (PBS). The other groups were treated with $100 \mu \mathrm{g}$ of free or encapsulated PS, co-delivered with inactivated PCV-II viruses $\left(1.05 \times 10^{6} 50 \%\right.$ tissue culture infective dose $\left[\mathrm{TCID}_{50}\right]$ per mouse). Mice were bled after first immunizations (Day 7 [D7], D14, and D21). All animalhandling procedures were performed according to the Guide for the Care and Use of Laboratory Animals of the National Institutes of Health and followed the guidelines of the Animal Welfare Act. All animal experiments were approved by the Nanjing Agricultural University Animal Care Committee.

\section{Determination of PCV-II-specific immunoglobulin $\mathrm{G}$ and its subclasses}

PCV-II-specific immunoglobulin G (IgG) levels were measured using modified enzyme-linked immunosorbent assay (ELISA) kits (Wuhankeqian Animal Biological Products Co, Ltd, Wuhan, People's Republic of China) for PCV-II. Briefly, the 96-well ELISA plates were washed three times with washing buffer. After washing, the plates were incubated with $100 \mu \mathrm{L}$ of $1: 400$ dilution of serum sample at $37^{\circ} \mathrm{C}$ for 30 minutes. The plates were then washed five times. Then, 1:5,000 goat anti-mouse total IgG-horseradish peroxidase conjugate was added to each well and incubated at $37^{\circ} \mathrm{C}$ for 30 minutes. After washing, $100 \mu \mathrm{L}$ of chromogenic agents $\mathrm{A}$ and $\mathrm{B}$ were added to each well and incubated at $37^{\circ} \mathrm{C}$ for 10 minutes. The reaction was stopped by adding $50 \mu \mathrm{L}$ of stop solution to each well. The optical density was then measured at $630 \mathrm{~nm}$ with a microplate reader. $\operatorname{IgG} 1, \operatorname{IgG} 2 \mathrm{a}, \operatorname{IgG} 2 \mathrm{~b}$, and IgG3 in the serum were determined using ELISA kits ( $R \& D$ Systems, Inc, Minneapolis, MN, USA).

\section{Determination of cytokine levels by ELISA}

$\mathrm{T}_{\mathrm{h}} 1$ cytokines (interferon [IFN]- $\gamma$, tumor necrosis factor [TNF]- $\alpha$, and interleukin [IL]-12p70), $\mathrm{T}_{\mathrm{h}} 2$ cytokine (IL-4), and $\mathrm{T}_{\mathrm{h}} 17$ cytokine (IL-17) in the serum from the various treatment groups were quantified using mouse ELISA cytokine kit (R\&D Systems, Inc).

\section{Flow cytometry analysis of DC activation}

DC activation was tested by removing sciatic and popliteal lymph nodes 24 hours and 48 hours after vaccination with different vaccine formulations, as described earlier. The lymph nodes were harvested and prepared into a cell suspension. The lymph node cells were then washed, blocked, and stained with antibodies (anti-CD11c-FITC, anti-major histocompatibility 
complex class II [MHCII]-PE and anti-CD86-PE-Cy5; all from BD Biosciences), and flow cytometry analysis was performed on a BD FACSVerse ${ }^{\mathrm{TM}}$ flow cytometer.

\section{Determination of antigen level in draining lymph nodes}

The neck and back of BALB/c mice were subcutaneously injected with different vaccine formulations containing $1.05 \times 10^{6} \mathrm{TCID}_{50}$ of antigen. At 7 days after immunization, lymph nodes from the sciatic and popliteal nodes were isolated, fixed in $4 \%$ paraformaldehyde, embedded in paraffin, and cut to yield $4 \mathrm{~mm}$ thick samples. After deparaffinization, samples were incubated with $3 \% \mathrm{H}_{2} \mathrm{O}_{2}$ for 10 minutes. Then, samples were blocked with goat serum and immunostained with antibody against PCV-II (Beijing Biosynthesis Biotechnology Co, Ltd, Beijing, People's Republic of China). A goat anti-rabbit secondary IgG and diaminobenzidine (ZSGB-Bio, Beijing, People's Republic of China) were used for color development. Specimens were stained with hematoxylin, and immunohistochemical micrographs were documented using an Olympus BX20 microscope (Tokyo, Japan).

\section{Determination of memory T-helper cells in draining lymph nodes}

Flow cytometry was performed to measure the percentage of memory T-helper cells in the lymph nodes obtained from immunized mice 7 days after the final immunization. Lymph nodes from the sciatic and popliteal regions were harvested and prepared with cell suspension. Cells were stained with anti-mouse antibodies (anti-CD4-PE, anti-CD44-PE-Cy5, anti-FITC-CD62L, and anti-allophycocyanin-C-C motif chemokine receptor type 7 [anti-APC-CCR7]; all from eBioscience, San Diego, CA, USA). The percentages of effector memory T-cells (TEM, CD4 ${ }^{+} \mathrm{CD} 44^{+} \mathrm{CD} 62 \mathrm{~L}^{-} \mathrm{CCR} 7$ and central memory T-cells (TCM, CD4 ${ }^{+} \mathrm{CD} 44^{+} \mathrm{CD} 62 \mathrm{~L}^{+} \mathrm{CCR} 7^{+}$) were determined using BD FACSVerse ${ }^{\mathrm{TM}}$ flow cytometer.

\section{Results}

\section{Particle size and zeta potential of Cub-PS}

In this study, the cubosome dispersion was prepared as described previously, ${ }^{10}$ with slight modifications to achieve higher loading of PS in cubosomes. The encapsulation of
PS into cubosomes slightly changed the physicochemical properties as compared to the blank cubosome nanoparticles. Similar sizes were acquired for Cub and Cub-PS nanoparticles. Table 1 shows the particle size determined by DLS and demonstrates increasing particle size with added PS (Figure 1A). Both the particle size and zeta potential of $\mathrm{Cub}$ and Cub-PS were similar (Table 1).

\section{SAXS studies}

In order to gain further insights into the nanostructural changes resulting from PS addition, we used SAXS to characterize the cubic phase of Cub-PS. The SAXS scattering curves for PS-containing cubosomes were obtained at $25^{\circ} \mathrm{C}$ for 30 minutes, as shown in Figure 1B. Intensity vs $q$ plots obtained from SAXS measurements of $\mathrm{Cub}$ and Cub-PS showed two strong diffraction peaks and a weak peak (arrows) for Cub-PS, with relative positions at ratios $\sqrt{2}: \sqrt{ } 3: \sqrt{ } 4$. These peaks are indicative of particles with a Pn3m nanostructure. The cubic liquid crystal structure was retained upon addition of PS to the cubosomes.

\section{Cryo-FESEM studies}

The morphology of Cub-PS was investigated by cryoFESEM. Cryo-FESEM paves the way for characterization of the surface structures in various nanostructured dispersions. The micrographs in Figure 2 show the images obtained for the dispersions of Cub-PS. Figure 2A shows Cub-PS with spherical morphology, whereas at high resolutions, Cub-PS (Figure 2B) shows a more cubic morphology compared with Cub (Figure 2C). Although the overall morphology of Cub-PS varied, the particles showed a similar microstructure to the cubic phase, indicating the same underlying tortuous structure and nodular surface features, entirely consistent with the structure previously described in the literature. ${ }^{17}$

\section{Cytotoxicity of cubosomes}

The cytotoxicity of cubosomes was evaluated using peritoneal macrophages of mice. Biocompatibility of cubosomes is a prerequisite for its adjuvant applications. The MTT assay (Figure 3A) indicates that the survival rate of peritoneal macrophages decreased with increasing lipid

Table I Characterization of PS-encapsulated cubosome nanoparticles

\begin{tabular}{llllll}
\hline Formulation & $\begin{array}{l}\text { Average } \\
\text { size }(\mathbf{n m})\end{array}$ & PDI & $\begin{array}{l}\text { Zeta potential } \\
(\mathbf{m V})\end{array}$ & $\begin{array}{l}\text { PS encapsulation } \\
\text { efficiency }(\%)\end{array}$ & $\begin{array}{l}\text { PS (mg)/ } \\
\text { Phy (I g) }\end{array}$ \\
\hline Cub & $28 I .8 \pm 1.47$ & $0.149 \pm 0.004$ & $-14.33 \pm 0.75$ & - & - \\
Cub-PS & $324.4 \pm 2.05$ & $0.163 \pm 0.153$ & $-16.13 \pm 0.42$ & $89.5 \pm 3.51$ & 100 \\
\hline
\end{tabular}

Notes: Sizes, PDI, zeta potential, encapsulation efficiency, and loading levels are represented as mean \pm SEM from various batches prepared.

Abbreviations: Cub, cubosomes; Cub-PS, cubosome-polysaccharide nanoparticles; Phy, phytantriol; PS, polysaccharides; PDI, polydispersity index; SEM, standard error of the mean. 

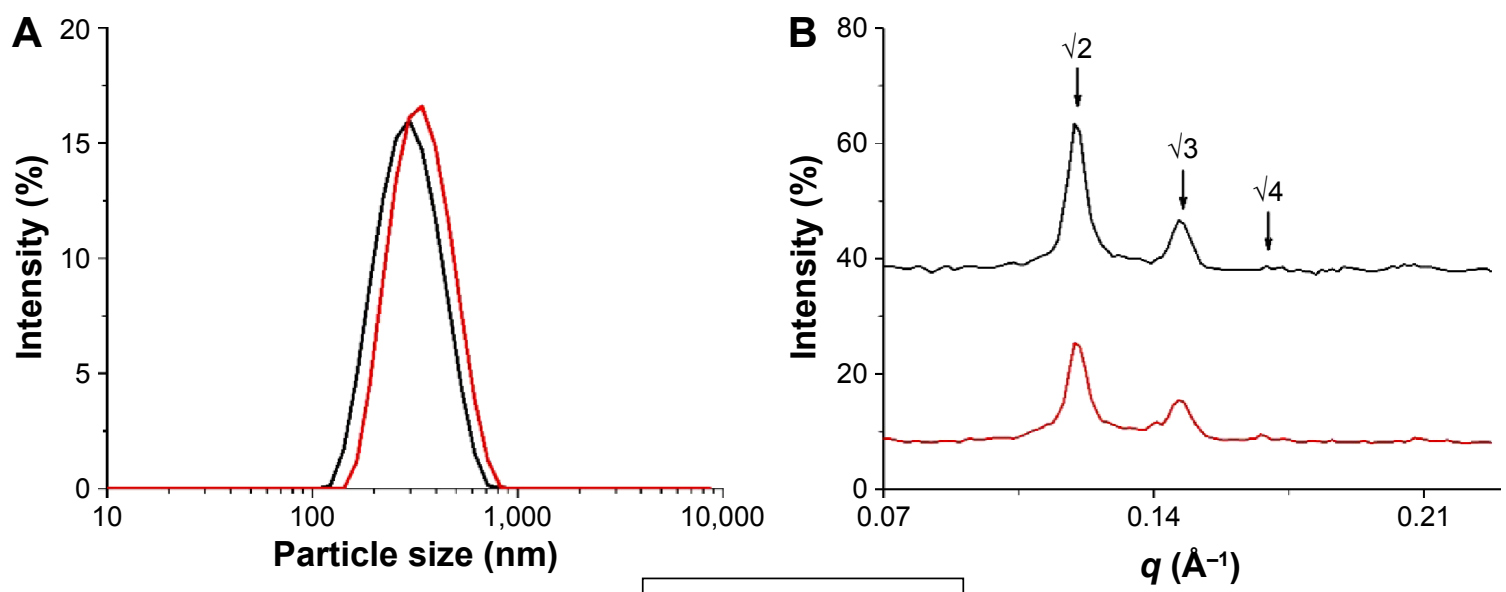

Figure I Particle size and SAXS studies.

Notes: (A) The particle size of Cub and Cub-PS; (B) SAXS patterns of Cub and Cub-PS.

Abbreviations: Cub, cubosomes; Cub-PS, cubosome-polysaccharide nanoparticles; SAXS, small-angle X-ray scattering.

\section{Cub-PS}

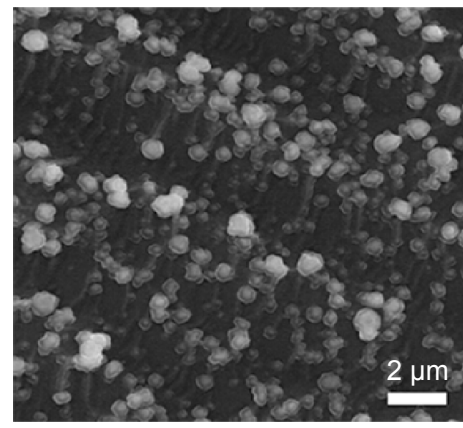

Cub-PS

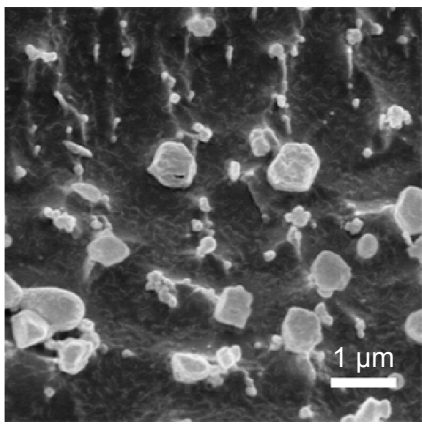

Cub

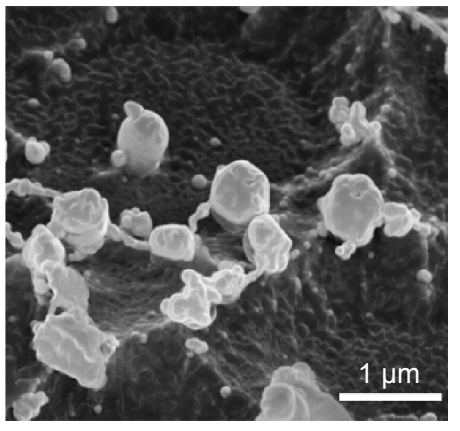

Figure 2 Cryo-FESEM micrographs of Cub and Cub-PS.

Abbreviations: Cub-PS, cubosome-polysaccharide nanoparticles; cryo-FESEM, cryo-field emission scanning electron microscopy.
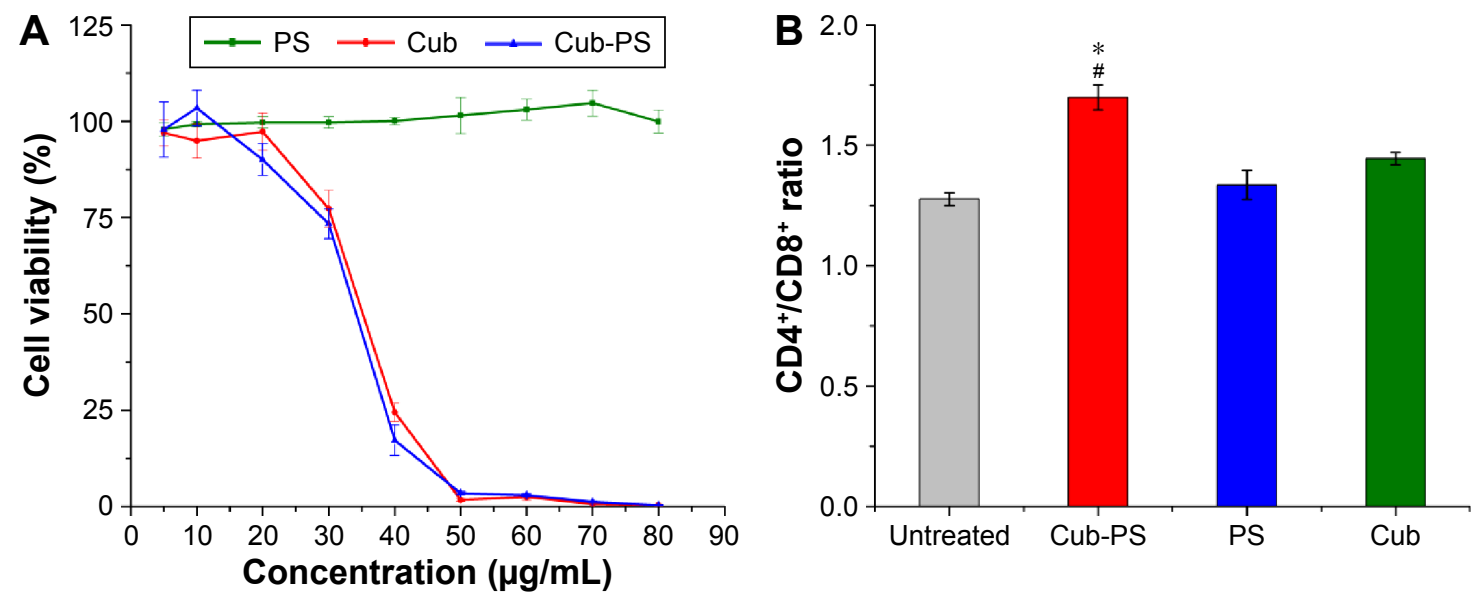

Figure 3 Cell viability of macrophages and change in $\mathrm{CD}^{+}$to $\mathrm{CD}^{+} \mathrm{T}$-cell ratio.

Notes: (A) Cell viability of macrophages incubated in the presence of blank Cub and PS-containing cubosome dispersions (Cub-PS) and PS after 24 hours of incubation. (B) The ratio of $C D 4^{+}$to $C D 8^{+}$T-cells increased markedly after total spleen cells were incubated for 48 hours. Data are expressed as the mean \pm SEM. $* P<0.05$ vs the PS group, while ${ }^{\#} P<0.05$ vs the Cub group.

Abbreviations: Cub, cubosomes; Cub-PS, cubosome-polysaccharide nanoparticles; PS, polysaccharides; SEM, standard error of the mean. 
concentration, and a significant difference in survival rate for the cells treated with $30 \mu \mathrm{g} / \mathrm{mL}$ of lipid (phytantriol) was observed. However, no significant difference was found for PS-loaded or blank cubosomes in all investigated ranges. Hinton et al reported a similar cytotoxicity of phytantriol cubosomes in Chinese hamster ovary or A549 cells, and phytantriol cubosomes result in disruption of cell membrane integrity and inhibition of cell membrane remodeling via macropinocytosis. ${ }^{18}$

\section{Activation of $\mathrm{CD}^{+}$and $\mathrm{CD} 8^{+}$T-cells}

The total sample of spleen cells isolated from mice was cultured in 24-well plates in the presence of cubosomes for 48 hours. Normal cultured cells were used as negative controls. After incubation for 48 hours, the ratio of $\mathrm{CD}^{+}{ }^{+}$to $\mathrm{CD}^{+}$ T-cells markedly increased in the Cub-PS group compared with PS and Cub groups $(P<0.05)$ (Figure 3B). Thus, CD $4^{+}$ $\mathrm{T}$-cells may play an indispensable role in adjuvant activity.

\section{Systemic antibody responses in vaccinated mice}

Some researchers have demonstrated that cubosomes are potent adjuvants for immunization. ${ }^{11,19}$ On the basis of recent observations that delivery of antigens and toll-like receptor ligands in separate nanoparticles induces a stronger antibody response than co-delivery by the same nanoparticle, ${ }^{13,14}$ we evaluated the immunostimulatory potential of PS, cubosomes (Phy, $1 \mathrm{mg}$ per animal), and cubosomes (Phy, $1 \mathrm{mg}$ per animal) carrying PS (100 $\mu \mathrm{g}$ per animal) coadministered with inactivated PCV-II virus into $\mathrm{BALB} / \mathrm{c}$ mice.

To examine whether the response was dose dependent, we administered one of the following: $4 \times$ Cub-PS-Ag, $2 \times$ Cub-PS-Ag, or Cub-PS-Ag containing $1.05 \times 10^{6}$ TCID $_{50}$ Ag per injection. During the immunization process, sera were obtained from mice of all groups, and PCV-II IgG titers were measured. Determination of antibody responses on D21 showed that Cub-PS-Ag induced significantly higher PCV-II-specific antibody titers in comparison to the $4 \times \mathrm{Cub}$ PS-Ag and $2 \times$ Cub-PS-Ag treatments $(P<0.05$; Figure $4 \mathrm{~A})$. As shown in Figure 4B, on D7 (priming), no significant differences were observed between the groups immunized with PS-Ag, Cub-Ag alone, and Cub-PS-Ag in terms of the IgG responses. However, encapsulation of PS into cubosomes significantly increased the antibody responses compared to free PS and Cub-Ag alone from D14-D21.

Adjuvants can induce changes in $\mathrm{T}_{\mathrm{h}} 1-\mathrm{T}_{\mathrm{h}} 2$ balance and, therefore, in the antibody subclass generated. In mice, IgG1 is associated with a $T_{h}$ 2-like response, while a $T_{h} 1$ response is associated with the induction of $\operatorname{IgG} 2 \mathrm{a}, \operatorname{IgG} 2 \mathrm{~b}$, and $\mathrm{IgG} 3$ antibodies. ${ }^{20}$ Within all the groups, the encapsulation of PS in cubosomes resulted in higher antibody titers for all subtypes (IgG1, IgG2a, IgG2b, and IgG3), as shown in Figure $4 \mathrm{C}$ and $\mathrm{D}$, indicating that Cub-PS-Ag promoted a mixed $\mathrm{Th} 1 / \mathrm{Th} 2$ response.

\section{Cytokine levels}

The levels of IFN- $\gamma$, TNF- $\alpha$, IL-4, IL-12p70, and IL-17 in serum were measured by ELISA at weekly intervals from D7 to D21 after final vaccination. As shown in Figure 5A, the production of IL-4 was detectable in all vaccinated mice beginning at D7 and reached peak levels at D21. Mice vaccinated with Cub-PS-Ag generated significantly higher levels of IL-4 compared to mice receiving PS-Ag or Cub-Ag alone. Unexpectedly, Cub-PS-Ag did not generate higher levels of IL-12p70 cytokine (Figure 5B), which may be due to the balance of numerous cytokines. The production of IFN- $\gamma$ reached peak levels at D21 and was significantly higher than that induced by Cub-Ag or PS-Ag alone at D7 and D21 (Figure 5C). Similar TNF- $\alpha$ and IL-17 cytokine levels were detectable in serum from mice immunized with Cub-PS-Ag, which remained stable and were significantly higher than those obtained for antigen mixed with $\mathrm{Cub}$ or PS alone (Figure 5D and E).

On the whole, Cub-PS-Ag induced secretion of higher levels of $T_{h} 1, T_{h} 2$, and $T_{h} 17$ cytokines in the serum, indicating stronger immune responses, which was consistent with the significantly higher level of antibody subtypes.

\section{Activation and maturation of DCs in the lymph nodes}

After having confirmed the adjuvant potential of Cub-PS, we next wondered if it affected vaccine potency in terms of activating DCs in the draining lymph nodes. To address this question, we first examined their efficiency in activating DCs in vivo. Vaccine formulations were subcutaneously injected into the tail base of each mouse and then the upregulation of activation markers by DCs in the draining lymph nodes was examined. In the study, we divided the mice into five groups and injected them with PBS, Cub-PS-Ag, Cub-Ag, PS-Ag, and ISA206, respectively. At 24 hours and 48 hours after the injection, cells in the sciatic and popliteal lymph nodes were collected and analyzed by fluorescence-activated cell sorting.

Mice injected with Cub-PS-Ag displayed considerably higher frequencies of CD $11 \mathrm{c}^{+} \mathrm{MHC}$ II or CD11 $\mathrm{c}^{+} \mathrm{CD} 86^{+} \mathrm{DCs}$ than mice injected with Cub-Ag, PS-Ag and PBS, suggesting elevated recruitment and maturation of DCs into these lymph nodes (Figure 6A and B). 

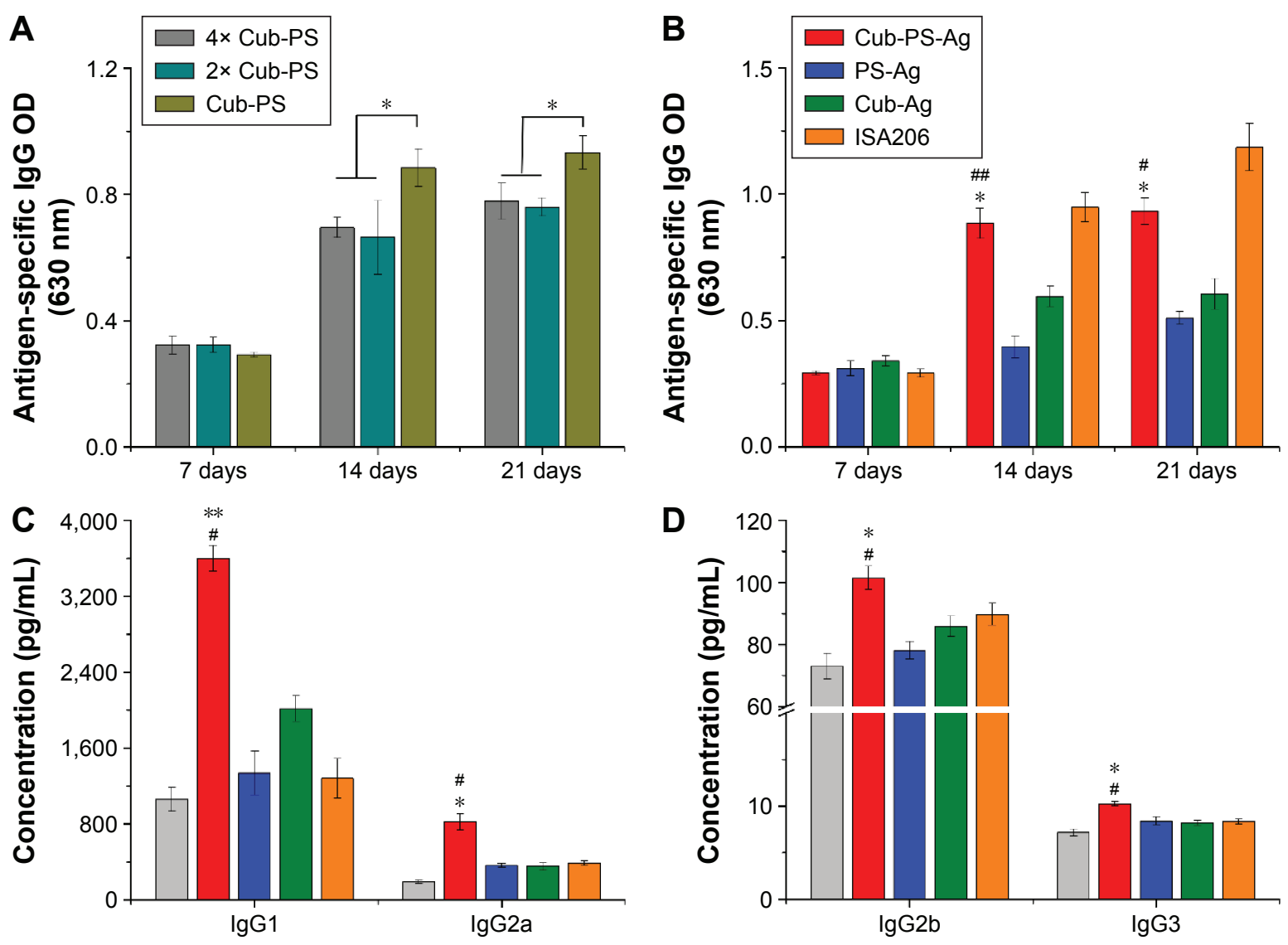

$\square$ PBS $\square$ Cub-PS-Ag $\square$ PS-Ag $\square$ Cub-Ag $\square$ ISA206

Figure 4 Cub-PS eliciting strong antigen-specific antibody and antibody subclass responses in vivo.

Notes: (A) Antigen-specific lgG levels in the serum on injection of different contents of Cub-PS after first immunization. (B) Antigen-specific lgG levels in the serum at the indicated time points after first immunization. (C) $\lg G \mid$ and $\lg G 2 a$ levels in the serum of immunized mice $2 I$ days after the first immunization. (D) $\lg G 2 b$ and $\lg G 3$ levels in the serum of immunized mice 2 I days after the first immunization. Data are expressed as the mean \pm SEM. $* P<0.05$ and ${ }^{* * P}<0.0$ I vs the PS-Ag group; ${ }^{*} P<0.05$ and ${ }^{\# P} P<0.0$ I vs the Cub-Ag group.

Abbreviations: $\mathrm{Ag}$, antigen; Cub-Ag, mixture of cubosomes and Ag; Cub-PS-Ag, mixture of cubosome-polysaccharide nanoparticles and Ag; Ig, immunoglobulin; OD, optical density; PS-Ag, mixture of PS and Ag; SEM, standard error of the mean.

Further quantification of the percentage of CD11 $\mathrm{c}^{+} \mathrm{MHC} \mathrm{II}^{+}$ or $\mathrm{CD} 11 \mathrm{c}^{+} \mathrm{CD} 86^{+} \mathrm{DC}$ s based on the histograms showed that the DC maturation level induced by Cub-PS-Ag was significantly higher than that induced by PS-Ag alone (Figure 6C).

\section{Antigen transport into draining lymph nodes}

Because we observed that the Cub-PS-Ag formulation induces considerably higher frequencies of mature DC in the lymph nodes, we next wondered whether it affected antigen transport to the draining lymph nodes. To uncover the mechanisms underlying the enhanced immune responses, we determined the amount of available antigen in the draining lymph nodes by immunohistochemistry. On the seventh day postimmunization, the most abundant level of antigen was detected in the lymph nodes of mice immunized with CubPS-Ag, followed by mice immunized with PS-Ag vaccine formulation (Figure 7).

\section{Memory T-helper cells in draining lymph nodes}

T-follicular helper (Tfh) cells are a subset of $\mathrm{CD}^{+}{ }^{+} \mathrm{T}$-cells essential for generation of memory B-cells and long-lived plasma cells, and memory CD4+ Th cells also play an essential role in initiating immune responses..$^{21,22}$ Currently, two classes of memory Th cells have been distinguished: TEM and TCM. The former can display immediate effector T-cell function, whereas the latter are the reservoir of memory and effector T-cells, therefore being destined for initiating and long-term protection, respectively. ${ }^{23}$ In this study, Cub-PS-Ag significantly increased the percentage of TEM $\left(\mathrm{CD} 4{ }^{+} \mathrm{CD} 44^{+} \mathrm{CD} 62 \mathrm{~L}^{-} \mathrm{CCR} 7^{-}\right)$in the draining lymph nodes 7 days after first immunization (Figure 8). Furthermore, the percentage of $\mathrm{TCM}\left(\mathrm{CD} 4{ }^{+} \mathrm{CD} 44^{+} \mathrm{CD} 62 \mathrm{~L}^{+} \mathrm{CCR} 7^{+}\right)$was also determined in the draining lymph nodes of mice immunized with Cub-PS-Ag, Cub-Ag, PS-Ag, and ISA206, showing slightly detectable changes in these groups (Figure 8). The 

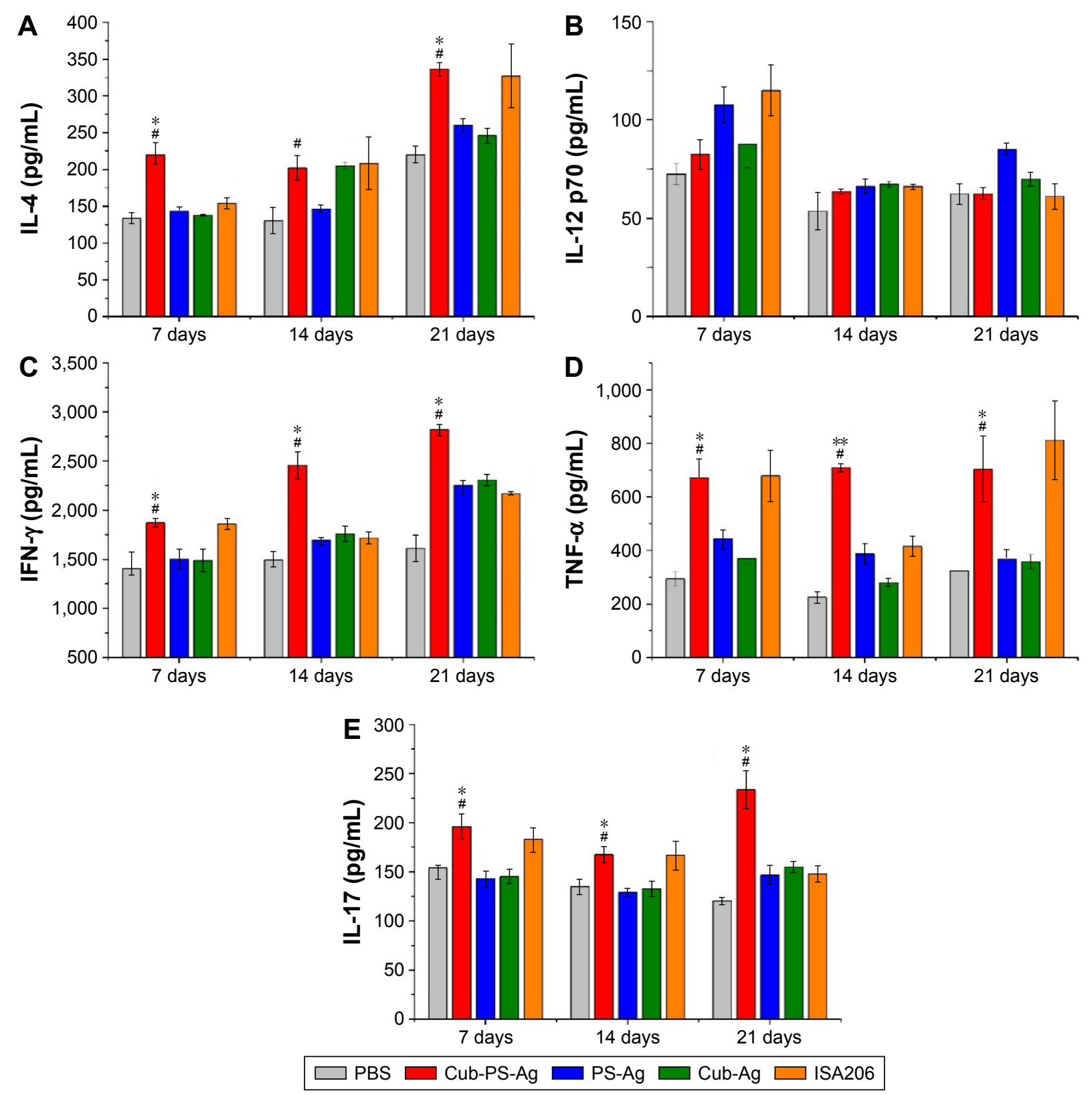

Figure 5 Production of cytokines in the serum of $B A L B / c$ mice.

Notes: (A) IL-4, (B) IL-12, (C) IFN- $\gamma$, (D) TNF- $\alpha$, and (E) IL-I7 at the indicated time points after first immunization were measured by ELISA. Data are expressed as the mean \pm SEM. $* P<0.05$ and $* * P<0.0$ I vs the PS-Ag group, while ${ }^{*} P<0.05$ vs Cub-Ag group.

Abbreviations: Ag, antigen; Cub-Ag, mixture of cubosomes and Ag; Cub-PS-Ag, mixture of cubosome-polysaccharide nanoparticles and Ag; ELISA, enzyme-linked immunosorbent assay; IFN, interferon; IL, interleukin; PBS, phosphate-buffered saline; PS-Ag, mixture of PS and Ag; TNF, tumor necrosis factor; SEM, standard error of the mean.

result indicated that Cub-PS-Ag vaccine formulation significantly increased the percentages of TEM and TCM in the draining lymph nodes 7 days after the first immunization.

\section{Discussion}

Particulate compounds, including biodegradable polymeric microparticles, emulsions, alum, and calcium phosphate, are the most widely used vehicle adjuvants. ${ }^{15}$ As an antigen delivery system, cubosomes have demonstrated large potential for the development of adjuvants. The cubosome structure consists of a highly twisted, continuous lipid bilayer with two congruent, nonintersecting water channels, giving the particle both hydrophobic and hydrophilic domains. This complex structure offers high loading of drugs and protects the encapsulated active contents from degradation and/or clearance. Their benefits are multifarious, ranging from the sustained delivery of adjuvants and antigens, to the targeting of antigen-presenting cells (APCs) through receptor-mediated 
A

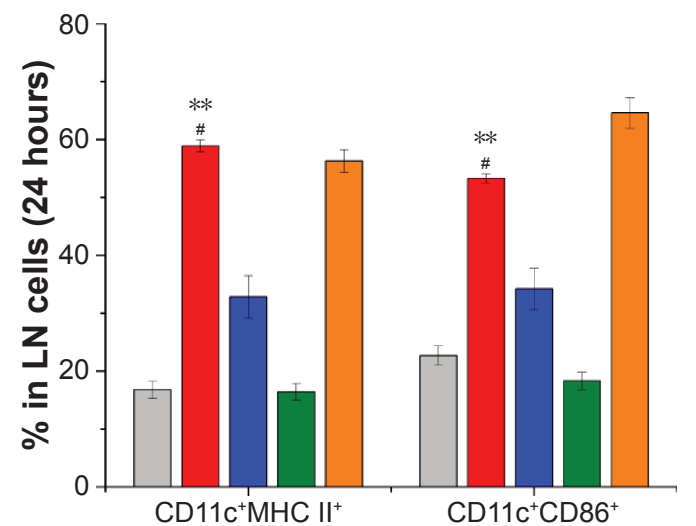

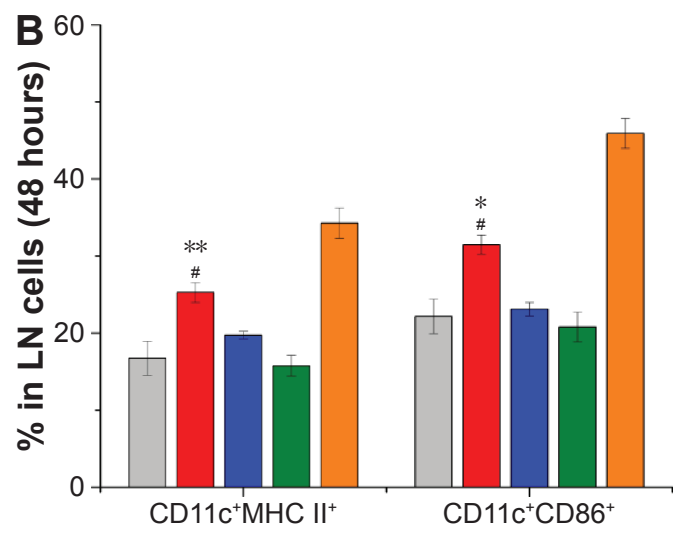

$\square$ PBS $\square$ Cub-PS-Ag $\square$ PS-Ag $\square$ Cub-Ag $\square$ ISA206

C

PBS
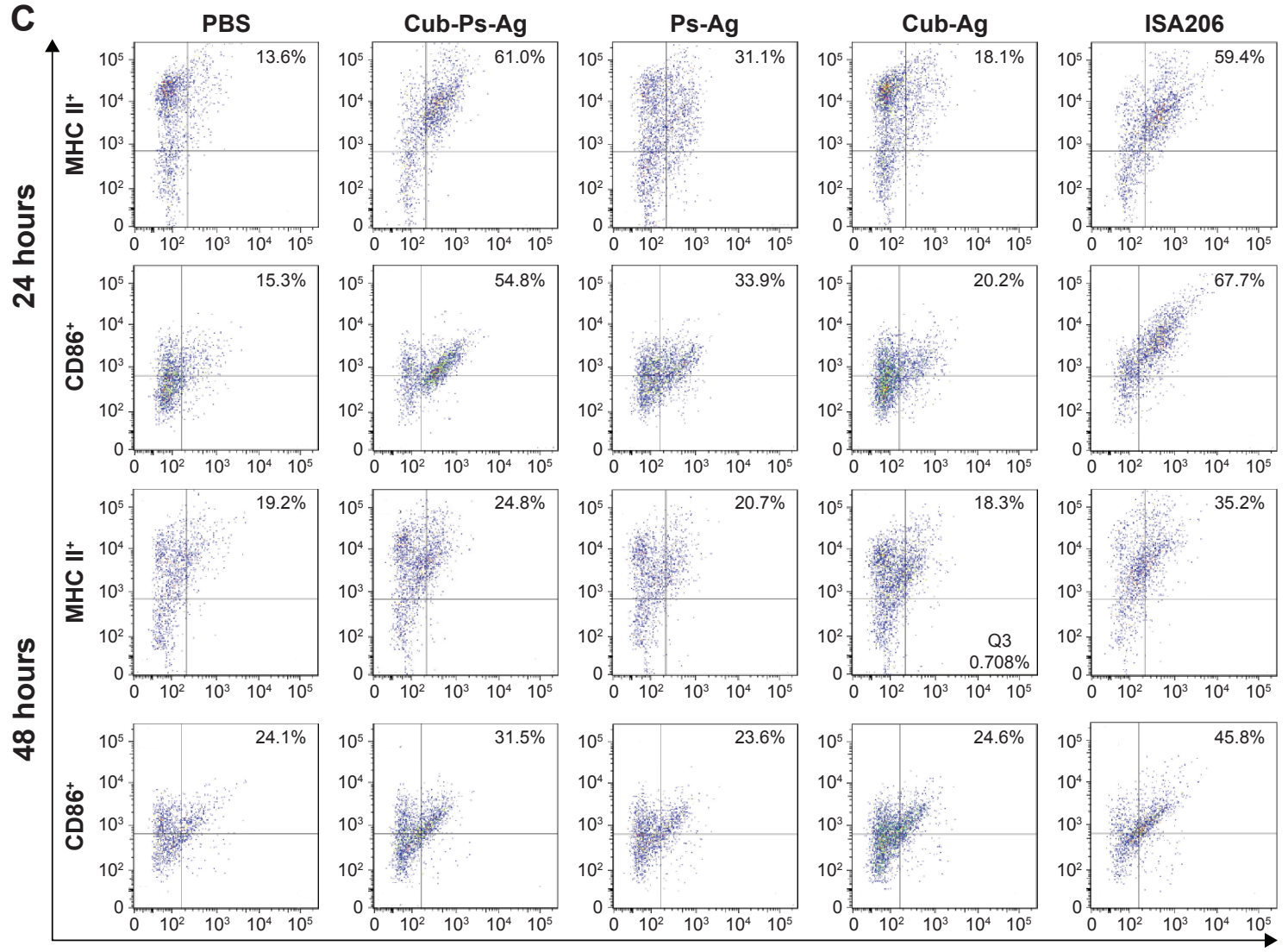

CD11c $^{+}$

Figure 6 Cub-PS activating DCs in the draining lymph nodes in vivo.

Notes: Percentage of CDI Ic $\mathrm{MHC} \mathrm{II}^{+}$and $\mathrm{CDI} \mathrm{Ic} \mathrm{C}^{+} \mathrm{CD} 86^{+}$cells in a total of 20,000 lymphocytes from naive mice or mice vaccinated with PS-Ag, Cub-Ag, Cub-PS-Ag, and ISA206 at (A) 24 hours and (B) 48 hours after subcutaneous injection. FACS plots in (C) are representative of the mean percentages of three mice in each group. Data are expressed as the mean \pm SEM. $* P<0.05$ and ${ }^{* *} P<0.0$ I vs the $P S-A g$ group, while ${ }^{\# P}<0.05$ vs Cub-Ag group.

Abbreviations: $\mathrm{Ag}$, antigen; $\mathrm{CD}$, cluster of differentiation; Cub-Ag, mixture of cubosomes and Ag; Cub-PS-Ag, mixture of cubosome-polysaccharide nanoparticles and Ag; DC, dendritic cells; FACS, fluorescence-activated cell sorting; LN, lymph node; MHC, major histocompatibility complex; PBS, phosphate-buffered saline; PS-Ag, mixture of PS and Ag; SEM, standard error of the mean.

or unspecific phagocytosis. In the past few decades, increasing research has focused on using cubosomes as carriers to enhance the effects of drugs, ${ }^{24}$ whereas few studies have focused on enhancing the adjuvant activity effects of PSs. In this study, we have investigated the ability of cubosomes, a novel lipid-based particulate drug delivery system, to generate strong cellular and humoral immune responses toward inactivated PCV-II virus in vivo, after encapsulation of PSs.

After identifying a successful formulation, the physicochemical characterization of Cub-PS was undertaken, as 

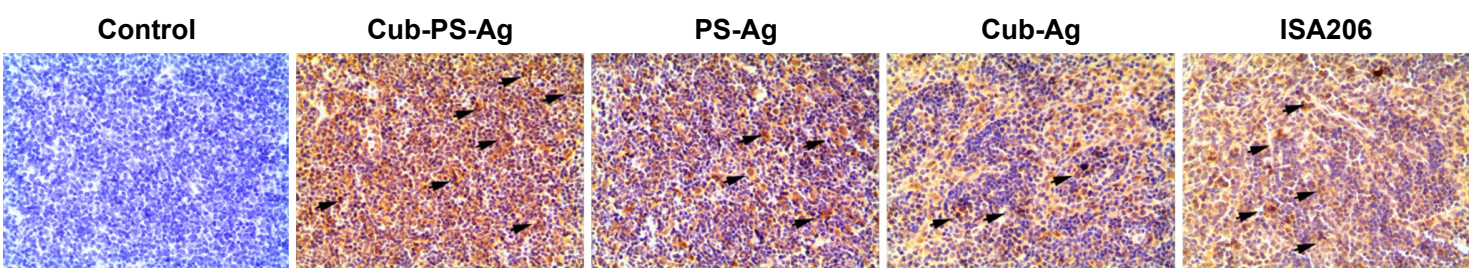

Figure 7 Available antigens in draining lymph nodes.

Notes: BALB/c mice were subcutaneously injected with PS-Ag, Cub-Ag, Cub-PS-Ag, and ISA206. Yellow areas indicated by arrows represent antigen.

Abbreviations: $\mathrm{Ag}$, antigen; Cub-Ag, mixture of cubosomes and Ag; Cub-PS-Ag, mixture of cubosome-polysaccharide nanoparticles and Ag; PS-Ag, mixture of PS and Ag.

these properties could influence the physical stability, structure, and content of the encapsulated drug. Cub-PS, with a diameter of $324.4 \pm 2.05 \mathrm{~nm}$, was advantageous for the passive targeting of APC due to enhanced permeability and retention effects. Furthermore, a zeta potential of $-16.13 \pm 0.42 \mathrm{mV}$ is sufficiently high to cause the Cub-PS moieties to repel each other, thereby avoiding particle aggregation and encouraging long-term stability.

To investigate this phase change in more detail and gain further insight into the nanostructural changes occurring in these nanoparticles with encapsulated PS, SAXS and cryoFESEM were performed on the Cub-PS dispersion. The locations of the three peaks suggest that the Pn $3 \mathrm{~m}$ cubic phase structure is retained in Cub-PS. ${ }^{25,26}$

Boyd et $\mathrm{al}^{26}$ have recently introduced the cryo-FESEM technique for directly investigating the three-dimensional and surface structures and to then confirm whether the investigated samples are cubosome particles. ${ }^{25,27}$ The cryo-FESEM images (Figure 2) show the presence of discrete colloidal nanoparticles spanning a size range of 300-400 nm, which was typical for these systems and consistent with the DLS traces observed. The Cub-PS sample shows nanostructured particles displaying surface structures and morphology typical of cubic phase materials.
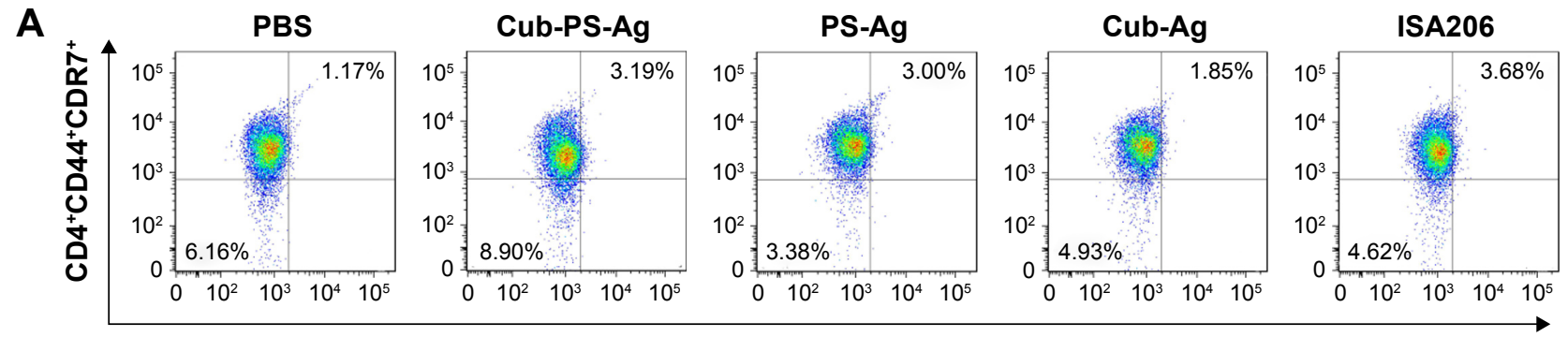

$\mathrm{CD}^{+} \mathrm{CD} 44^{+} \mathrm{CD} 6 \mathrm{~L}^{+}$

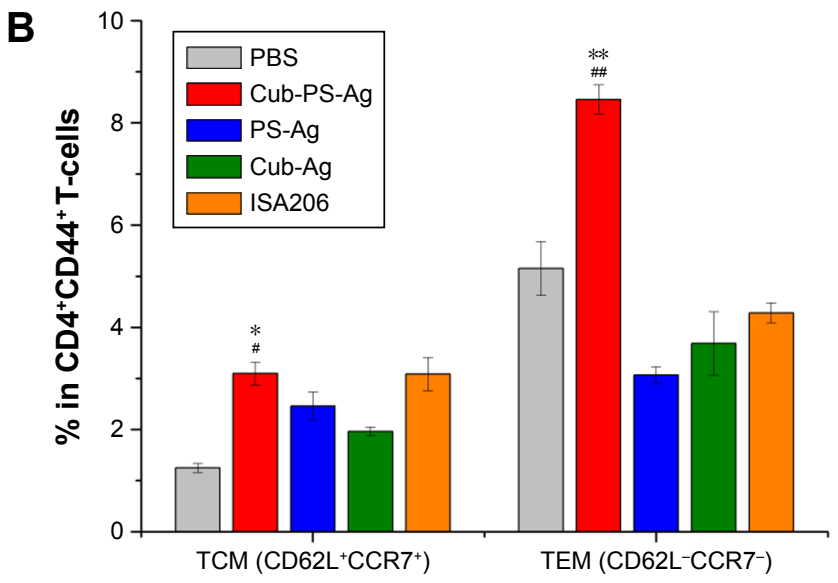

Figure 8 Frequency of central $\left(\mathrm{CD} 62 \mathrm{~L}^{+} \mathrm{CCR7} 7^{+}\right) /$effector (CD62L-CCR7 $\left.{ }^{-}\right)$memory $\mathrm{CD}^{+} \mathrm{CD}^{-} 4^{+} \mathrm{T}$-cells.

Notes: Mice were immunized with PS-Ag, Cub-Ag, Cub-PS-Ag, and ISA206. FACS plots in (A) are representative of the mean percentages of three mice in each group. The frequency of $(\mathbf{B}) \mathrm{CD} 4{ }^{+} \mathrm{CD} 44^{+} \mathrm{CD} 62 \mathrm{~L}^{+} \mathrm{CCR7} 7^{+} \mathrm{T}$-cells (TCM) and CD4 ${ }^{+} \mathrm{CD} 44^{+} \mathrm{CD} 62 \mathrm{~L}^{-} \mathrm{CCR} 7^{-} \mathrm{T}$-cells (TEM) were measured by flow cytometry. Data are expressed as the mean \pm SEM. $* P<0.05$ and $* * P<0.01$ vs the PS-Ag group, while ${ }^{*} P<0.05$ and ${ }^{\#} P<0.01$ vs Cub-Ag group.

Abbreviations: $\mathrm{Ag}$, antigen; $\mathrm{CCR}, \mathrm{C}-\mathrm{C}$ motif chemokine receptor; $\mathrm{CD}$, cluster of differentiation; Cub-Ag, mixture of cubosomes and Ag; Cub-PS-Ag, mixture of cubosomepolysaccharide nanoparticles and Ag; FACS, fluorescence-activated cell sorting; PBS, phosphate-buffered saline; PS-Ag, mixture of PS and Ag; TEM, effector memory T-cells; TCM, central memory T-cells; SEM, standard error of the mean. 
Immune regulation relies mainly on helper T-cells $\left(\mathrm{CD} 4^{+} \mathrm{T}\right)$ and cytotoxic T-cells $\left(\mathrm{CD} 8^{+} \mathrm{T}\right)$. Dynamic changes in the $\mathrm{CD} 4^{+} / \mathrm{CD} 8^{+}$ratio are regarded as constituting an important factor in determining immunity states and levels. In contrast, we observed that the ratio of $\mathrm{CD} 4^{+} / \mathrm{CD} 8^{+}$increased markedly after Cub-PS treatment, but not in the Cub and PS groups, and hence concluded that Cub-PS nanoparticles are capable of improving the immune functions of organisms.

After confirming the adjuvant activity of Cub-PS in vitro, we next investigated the effect of various vaccine formulations on antibody response. Serum IgG1, IgG2a, IgG2b, and IgG3 titers were then evaluated by ELISA.

Taken together, compared to the Cub-Ag and PS-Ag formulations, mice immunized with the Cub-PS-Ag vaccine formulation developed more potent antigen-specific IgG antibody responses, with higher levels of IgG1, IgG2a, $\mathrm{IgG} 2 \mathrm{~b}$, and IgG3. The results showed that Cub-PS-Ag elicited a mixed $T_{h} 1 / T_{h} 2$ immune response to inactivated PCV-II virus. Then, we found that Cub-PS-Ag formulation can induce a higher IL-17 level compared to other formulations, which indicated that it is capable of generating strong $\mathrm{T}_{\mathrm{h}}$ 17-based cell responses against PCV-II.

The process of generating an immune response to a vaccine greatly depends on the efficient uptake of the antigen by DCs and subsequent presentation of the antigen within the major lymphoid organs. ${ }^{28}$ Different vaccine formulations were subcutaneously injected at the neck and back of each mouse, and then the upregulation of activation markers by DCs in the draining lymph nodes was examined. Consequently, we investigated the DC recruitment and maturation levels of comparable PS-Ag and Cub-PS-Ag formulations. Taken together, Cub-PS-Ag could induce effective recruitment and expression of MHC-II and costimulatory molecules on DCs in the draining lymph nodes, both at 24 hours and 48 hours after immunization.

Considering the significant differences in DC recruitment and activation between various formulations, we wondered whether these differences affected antigen transport into draining lymph nodes. Therefore, the available antigens contained in the draining lymph nodes were determined over time by immunohistochemistry. At 7 days postimmunization, Cub-PS-Ag resulted in more abundant antigen transport into the draining lymph nodes than PS-Ag or Cub-Ag alone (Figure 7).

Taking these results into consideration, our results indicated that Cub-PS-Ag effectively promoted adequate initial antigen exposure. In successfully vaccinated individuals, regulatory $\mathrm{T}$-cell, antigen-specific memory $\mathrm{B}-$ cells, and memory T-cells provide this protection against infectious agents..$^{29-31}$ Of the two types of memory T-cells, TCM are not available in sufficient quantities early in infection, delivering peak effector responses only after they have undergone antigen-stimulated clonal expansion, differentiation, and trafficking. ${ }^{32}$ Therefore, we assessed the memory T-cell populations raised in response to the formulations. On D7 following the first immunization, the percentages of TEM and TCM were higher in mice immunized with Cub-PS-Ag than in mice immunized with PS-Ag or Cub-Ag alone (Figure 8). This is the first report about the effect of cubosomes on TEM or TCM. Elucidating this mechanism will be greatly helpful for the rational design of cubosome-based vaccines to establish the memory T-cell response at potential sites of virus replication and control infection at early stages.

Adjuvants are classified into three groups, including 1) active immunostimulants, being substances that increase the immune response to the antigen; 2) carriers; and 3) vehicle adjuvants, which serve as a matrix for antigens as well as for stimulating the immunity. ${ }^{33}$ In this study, cubosomes enclosing PS can play two roles in promoting the immunogenicity of inactivated virus vaccines. The mechanism underlying the action of Cub-PS as vaccine adjuvant is shown in Figure 9. First, Cub-PS can act as an effective active immunostimulant to promote antigen transport into draining lymph nodes. Second, it can enhance levels of DC recruitment and maturation to initiate and amplify the immune responses. Usually, most vaccine adjuvants do not act directly on T-cells but exert their functions indirectly via effects on APCs. Among the APCs, DCs are the most effective at inducing activation and proliferation of naïve T-cells in vitro and in vivo. Overall, our results showed that Cub-PS can promote antigen transport into draining lymph nodes greatly and facilitate DC maturation, which may provide promising adjuvant candidates for application. Thus, the detailed mechanisms of the role of Cub-PS as an adjuvant warrant further investigation in future.

\section{Conclusion}

Our results clearly demonstrate that the bottom-up process is very efficient in encapsulating PS into cubosome nanoparticles without any loss of their immune properties. This study investigated the adjuvant activity of PS after encapsulation within cubosomes. The results showed that PS encapsulated in cubosomes elicited more potent antigen-specific immune responses than PS-Ag alone or Cub-Ag formulations. The enhanced immune responses of Cub-PS-Ag might be attributed to the promotion of antigen transport into draining 


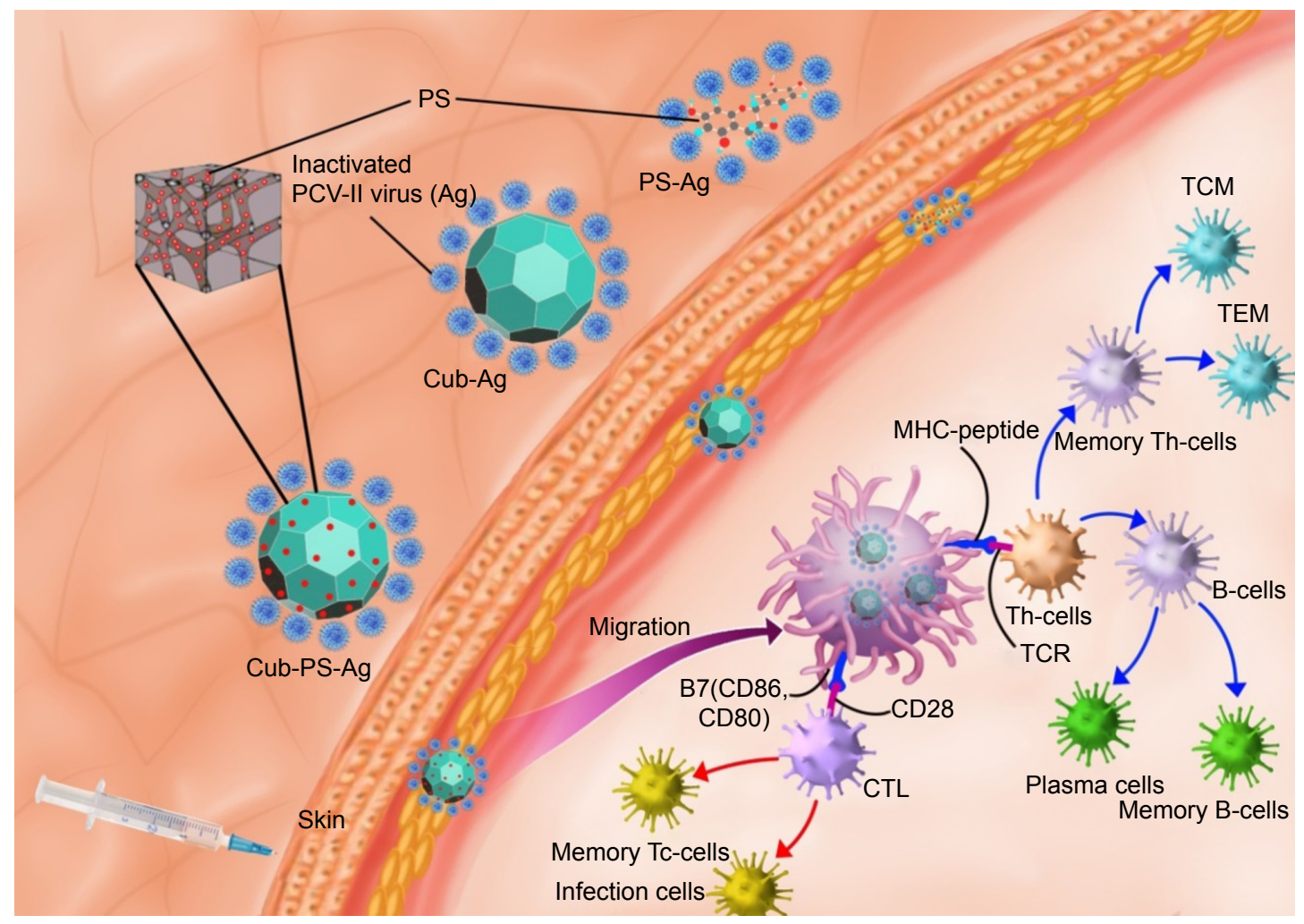

Figure 9 The possible mechanism of Cub-PS action as vaccine adjuvants.

Notes: Cub-PS was mixed with inactivated PCV-II viruses and the Cub-PS-Ag formulation is formed. After subcutaneous injection of Cub-PS-Ag formulation, APCs, especially DCs located in the subcutaneous region, can phagocytose the Cub-PS-Ag, process the antigens during the migration to secondary lymph nodes, and become mature. At this moment, DCs present the MHC-peptide complex to T-cells at lymph nodes. CD80 and CD86 are highly expressed on the surface of DCs. Subsequently, some of the T- and B-cells become memory cells and protect the organism upon a second encounter with the same pathogen.

Abbreviations: Ag, antigen; CTL, cytotoxic T-lymphocyte; Cub-Ag, mixture of cubosomes and Ag; Cub-PS-Ag, mixture of cubosome-polysaccharide nanoparticles and Ag; DC, dendritic cell; MHC, major histocompatibility complex; PCV, porcine circovirus; PS-Ag, mixture of PS and Ag; TCM, central memory T-cells; TCR, T-cell receptor; TEM, effector memory T-cells; Th-cells, T-helper cells; Tc-cells, cytotoxic T cells.

lymph nodes, efficient induction of DC activation, and increased memory $\mathrm{T}$-helper cell differentiation in draining lymph nodes. These results demonstrate that cubosomes can enhance the adjuvant activity of immunostimulants. Understanding the effects of the Cub-PS-Ag formulations on the resultant immune responses might have significant implications for rational vaccine design.

\section{Acknowledgments}

The project was supported by the National Natural Science Foundation of China (grant number 31372472), the Special Fund for Agro-Scientific Research in the Public Interest (grant numbers 201303046 and 201403051), and a project funded by the Priority Academic Program Development of Jiangsu Higher Education Institutions. We are grateful to Professor Yuanliang Hu, Professor Jiaguo Liu, PhD, Yi Wu, and all other staff in the Institute of Traditional Chinese Veterinary Medicine of Nanjing Agricultural University for their assistance in the experiments.

\section{Disclosure}

The authors report no conflicts of interest in this work.

\section{References}

1. Pavot V, Rochereau N, Primard C, et al. Encapsulation of Nod1 and Nod2 receptor ligands into poly(lactic acid) nanoparticles potentiates their immune properties. J Control Release. 2013;167(1):60-67.

2. Wang W, Singh M. Selection of adjuvants for enhanced vaccine potency. World J Vaccines. 2011;1(2):33.

3. Coffman RL, Sher A, Seder RA. Vaccine adjuvants: putting innate immunity to work. Immunity. 2010;33(4):492-503.

4. De Haan A, Tomee J, Huchshorn J, Wilschut J. Liposomes as an immunoadjuvant system for stimulation of mucosal and systemic antibody responses against inactivated measles virus administered intranasally to mice. Vaccine. 1995;13(14):1320-1324.

5. Kasturi SP, Skountzou I, Albrecht RA, et al. Programming the magnitude and persistence of antibody responses with innate immunity. Nature. 2011;470(7335):543-547.

6. Fong W-K, Hanley T, Boyd BJ. Stimuli responsive liquid crystals provide 'on-demand'drug delivery in vitro and in vivo. $J$ Control Release. 2009;135(3):218-226.

7. Lopes LB, Lopes JL, Oliveira DC, et al. Liquid crystalline phases of monoolein and water for topical delivery of cyclosporin A: characterization and study of in vitro and in vivo delivery. Eur J Pharm Biopharm. 2006; 63(2):146-155. 
8. Angelova A, Angelov B, Lesieur S, et al. Dynamic control of nanofluidic channels in protein drug delivery vehicles. J Drug Deliv Sci Technol. 2008;18(1):41-45.

9. Leser ME, Sagalowicz L, Michel M, Watzke HJ. Self-assembly of polar food lipids. Adv Colloid Interface Sci. 2006;123-126:125-136.

10. Shen HH, Lake V, Le Brun AP, et al. Targeted detection of phosphatidylserine in biomimetic membranes and in vitro cell systems using annexin V-containing cubosomes. Biomaterials. 2013;34(33):8361-8369.

11. Rizwan SB, McBurney WT, Young K, et al. Cubosomes containing the adjuvants imiquimod and monophosphoryl lipid A stimulate robust cellular and humoral immune responses. J Control Release. 2013; 165(1):16-21.

12. Pi CC, Chu CL, Lu CY, et al. Polysaccharides from Ganoderma formosanum function as a Th1 adjuvant and stimulate cytotoxic $\mathrm{T}$ cell response in vivo. Vaccine. 2014;32(3):401-408.

13. Liu Z, Ma X, Deng B, et al. Development of liposomal Ganoderma lucidum polysaccharide: formulation optimization and evaluation of its immunological activity. Carbohydr Polym. 2015;117:510-517.

14. Kazzaz J, Singh M, Ugozzoli M, Chesko J, Soenawan E, O’Hagan DT. Encapsulation of the immune potentiators MPL and RC529 in PLG microparticles enhances their potency. J Control Release. 2006;110(3): 566-573.

15. Singh M, Chakrapani A, O'Hagan D. Nanoparticles and microparticles as vaccine-delivery systems. Expert Rev Vaccines. 2007;6(5):797-808.

16. Ye Y, Huang X, Zhang Y, et al. Calcium influx blocked by SK\&F 96365 modulates the LPS plus IFN- $\gamma$-induced inflammatory response in murine peritoneal macrophages. Int Immunopharmacol. 2012;12(2): 384-393.

17. Rizwan SB, Dong YD, Boyd BJ, Rades T, Hook S. Characterisation of bicontinuous cubic liquid crystalline systems of phytantriol and water using cryo field emission scanning electron microscopy (cryo FESEM). Micron. 2007;38(5):478-485.

18. Hinton TM, Grusche F, Acharya D, et al. Bicontinuous cubic phase nanoparticle lipid chemistry affects toxicity in cultured cells. Toxicol Res. 2014;3(1):11-22.

19. Kojarunchitt T, Baldursdottir S, Dong YD, Boyd BJ, Rades T, Hook S. Modified thermoresponsive poloxamer 407 and chitosan sol-gels as potential sustained-release vaccine delivery systems. Eur J Pharm Biopharm. 2015;89:74-81.

20. Lefeber DJ, Benaissa-Trouw B, Vliegenthart JF, et al. Th1-directing adjuvants increase the immunogenicity of oligosaccharide-protein conjugate vaccines related to Streptococcus pneumoniae type 3. Infect Immun. 2003;71(12):6915-6920.
21. McHeyzer-Williams M, Okitsu S, Wang N, McHeyzer-Williams L. Molecular programming of B cell memory. Nat Rev Immunol. 2012; 12(1):24-34

22. Henriksen-Lacey M, Christensen D, Bramwell VW, et al. Comparison of the depot effect and immunogenicity of liposomes based on dimethyldioctadecylammonium (DDA), 3 $\beta-\left[\mathrm{N}-\left(\mathrm{N}^{\prime}, \mathrm{N}^{\prime}\right.\right.$-dimethylaminoethane) carbomyl] cholesterol (DC-Chol), and 1, 2-dioleoyl-3-trimethylammonium propane (DOTAP): prolonged liposome retention mediates stronger Th1 responses. Mol Pharm. 2010;8(1):153-161.

23. Sallusto F, Geginat J, Lanzavecchia A. Central memory and effector memory T cell subsets: function, generation, and maintenance. Annu Rev Immunol. 2004;22:745-763.

24. Liu H, Wang Y, Wang Q, et al. Protein-bearing cubosomes prepared by liquid precursor dilution: inner ear delivery and pharmacokinetic study following intratympanic administration. J Biomed Nanotechnol. 2013; 9(10):1784-1793.

25. Yaghmur A, Glatter O. Characterization and potential applications of nanostructured aqueous dispersions. Adv Colloid Interface Sci. 2009; 147-148:333-342.

26. Boyd BJ, Rizwan SB, Dong YD, Hook S, Rades T. Self-assembled geometric liquid-crystalline nanoparticles imaged in three dimensions: hexosomes are not necessarily flat hexagonal prisms. Langmuir. 2007;23(25):12461-12464.

27. Sagalowicz L, Michel M, Adrian M, et al. Crystallography of dispersed liquid crystalline phases studied by cryo-transmission electron microscopy. J Microsc. 2006;221(pt 2):110-121.

28. Gao W, Fang RH, Thamphiwatana S, et al. Modulating antibacterial immunity via bacterial membrane-coated nanoparticles. Nano Lett. 2015; 15(2):1403-1409.

29. Xu L, Liu Y, Chen Z, et al. Morphologically virus-like fullerenol nanoparticles act as the dual-functional nanoadjuvant for HIV-1 vaccine. Adv Mater. 2013;25(41):5928-5936.

30. Le DT, Jaffee EM. Regulatory T-cell modulation using cyclophosphamide in vaccine approaches: a current perspective. Cancer Res. 2012; 72(14):3439-3444.

31. del Pozo Balado Mdel M, Leal M, Méndez Lagares G, et al. Increased regulatory $\mathrm{T}$ cell counts in $\mathrm{HIV}$-infected nonresponders to hepatitis $\mathrm{B}$ virus vaccine. J Infect Dis. 2010;202(3):362-369.

32. Robinson HL, Amara RR. T cell vaccines for microbial infections. Nat Med. 2005;11(4):S25-S32.

33. Xu L, Liu Y, Chen Z, et al. Surface-engineered gold nanorods: promising DNA vaccine adjuvant for HIV-1 treatment. Nano Lett. 2012 12(4):2003-2012.
International Journal of Nanomedicine

\section{Publish your work in this journal}

The International Journal of Nanomedicine is an international, peerreviewed journal focusing on the application of nanotechnology in diagnostics, therapeutics, and drug delivery systems throughout the biomedical field. This journal is indexed on PubMed Central, MedLine, CAS, SciSearch $®$, Current Contents $\AA /$ Clinical Medicine,

\section{Dovepress}

Journal Citation Reports/Science Edition, EMBase, Scopus and the Elsevier Bibliographic databases. The manuscript management system is completely online and includes a very quick and fair peer-review system, which is all easy to use. Visit http://www.dovepress.com/ testimonials.php to read real quotes from published authors. 